\title{
PANORAMA DOS CURSOS PROFISSIONALIZANTES DE NÍVEL MÉDIO PRESENCIAL DA REDE ESTADUAL DE ENSINO DO ESTADO DO PARANÁ
}

\author{
Eduardo Henrique Baltrusch de Gois* \\ *E-mail: baltrusch@hotmail.com \\ Universidade Paranaense, Brasil \\ DOI: $10.15628 /$ rbept.2020.8818
}

Artigo submetido em jul/2019 e aceito em dez/2019

\begin{abstract}
RESUMO
A educação profissional teve início ainda no Brasil colônia, porém no decorrer dos anos, foi sendo incorporada ao sistema de ensino básico por vários decretos e Leis. O intuito deste trabalho é levantar um breve histórico da Educação profissional no Brasil e realizar um panorama da oferta de cursos profissionalizantes de nível médio presencial da rede estadual de ensino no Estado do Paraná. Em 2018 existiam 70.352 estudantes matriculados em 55 cursos técnicos distribuídos em 183 municípios, totalizando 351 estabelecimentos de ensino. Para o ano de 2019 estão sendo ofertadas 26.800 vagas. Além disso, esses cursos técnicos abrangem a maioria dos setores da economia (cultura, turismo, indústria, comércio, saúde, agropecuário, entre outros), sendo assim de suma importância para o desenvolvimento econômico e social da população paranaense.
\end{abstract}

Palavras-Chave: Ensino Técnico; Nível Médio; Ensino Profissional.

\section{OVERVIEW OF PROFESSIONAL TRAINING COURSES AT SECONDARY SCHOOL LEVEL IN THE PARANÁ STATE EDUCATIONAL NETWORK}

\begin{abstract}
Professional education began in Brazil colony, but over the years, was incorporated into the basic education system by various decrees and laws. The purpose of this paper is to present a brief history of professional education in Brazil and to provide an overview of the offer of professional level courses at the state level of education in the State of Paraná. In 2018 there were 70,352 students enrolled in 55 technical courses distributed in 183 municipalities, totaling 351 educational establishments. For the year 2019, 26,800 vacancies are being offered. In addition, these technical courses cover most of the sectors of the economy (culture, tourism, industry, commerce, health, agriculture, among others), and are therefore of paramount importance for the economic and social development of the population of Paraná.
\end{abstract}

Keywords: Professional Education; Secondary School; Technical Education. 


\section{INTRODUÇÃO}

A educação profissional teve início ainda no Brasil colônia, porém no decorrer dos anos está, foi sendo incorporada ao sistema de ensino básico por vários decretos e Leis. Contudo o início oficial desta modalidade de educação deu-se em 1909, com a criação do Decreto n.ำ 7.566 .

A educação profissional é de suma importância para o país, pois fornece aos estudantes (do ensino médio) uma forma rápida e eficiente de entrar no mercado de trabalho, aumentando significativamente, as chances do primeiro emprego, ou fornecendo oportunidades para as pessoas que já estão trabalhando de crescerem na empresa, ou ainda, para os desempregados que procuram uma qualificação, para melhorar seu currículo e aumentar suas possibilidades de empregabilidade.

O Intuito deste trabalho é levantar um breve histórico da Educação profissional no Brasil e realizar um panorama da oferta de cursos profissionalizantes de nível médio presencial da rede estadual de ensino do Estado do Paraná.

O trabalho será estruturado, primeiro com uma breve introdução do tema abordado e os objetivos do trabalho, seguido de um breve histórico da educação profissional no Brasil e o panorama dos cursos técnicos profissionalizantes no Paraná, e finalizando com uma breve conclusão do tema.

\section{UM BREVE HISTÓRICO DA EDUCAÇÃO PROFISSIONAL NO BRASIL}

No período colonial foram criadas as corporações de Ofício, onde somente era permitido o acesso aos homens livres, proibindo o ingresso de escravos. Assim, a educação profissional no Brasil, iniciou-se sendo excludente e discriminatória (CANALI, 2009).

Com o Alvará de 1785, que determinava a proibição de unidades fabris, assim o desenvolvimento industrial no Brasil estagnou-se. Porém, com chegada da família real portuguesa em 1808, foi inaugurado, o primeiro estabelecimento profissionalizante público do Brasil, sendo este nomeado como o Colégio das Fábricas, este tinha o objetivo de atender à educação dos artistas e aprendizes vindos de Portugal (VIEIRA e DE SOUZA JUNIOR, 2006).

No período do Brasil Império, várias iniciativas voltadas à educação profissional foram implementadas, como as Casas de Educandos Artífices instaladas em 10 províncias, entre os anos de 1840 a 1865 (VIEIRA e DE SOUZA JUNIOR, 2006). 
O início oficial da Educação Profissional e Tecnológica no Brasil, deuse pelo Decreto n. -7.566 , de 23 de setembro de 1909, sancionado pelo Presidente Nilo Peçanha (Brasil, 1909).

A Constituição de 1937 foi a primeira, dentre as constituições do Brasil, a abordar especificamente o ensino profissional, técnico e industrial, Em 13 de janeiro de 1937, foi assinada a Lei n. .378 , transformando as Escolas de Aprendizes e Artífices em Liceus Profissionais, destinados ao ensino profissional de todos os ramos e graus (VIEIRA e DE SOUZA JUNIOR, 2006).

Em 1942, com a Reforma Capanema, iniciada pelo Decreto-lei $\mathrm{n}$. 4.422 (Brasil, 1942), esta reforma remodelou o ensino no Brasil. Também, em 1942 surgiu o chamado Sistema "S", com a fundação do Serviço Nacional de Aprendizagem Industrial (SENAI). Já em 1946, foram fundados o Serviço Nacional de Aprendizagem Comercial (SENAC), o Serviço Social do Comércio (SESC) e o Serviço Social da Indústria (SESI), aumentando assim, a oferta de educação profissional no país (VIEIRA e DE SOUZA JUNIOR, 2006).

A Lei 4.024/1961 foi a primeira, Lei de Diretrizes e Bases da Educação brasileira (LDB), (Brasil, 1961). Essa LDB considerou pela primeira vez, a inclusão do ensino profissional ao sistema regular de ensino (VIEIRA e DE SOUZA JUNIOR, 2006).

Com o início do governo militar em 1964, e a criação da Lei n. ํ 5.692/71 a educação brasileira sofreu algumas alterações, como a oferta do ensino médio profissionalizante para todos (Brasil, 1971).

Em 1990, foram criados o Serviço Nacional de Aprendizagem Rural (SENAR), o Serviço Nacional do Transporte (SENAT), o Serviço Nacional de Apoio ao Cooperativismo (SESCOOP) e o Serviço Brasileiro de Apoio à Pequena e Média Empresa (SEBRAE), aumentando ainda mais, a oferta de educação profissional no Brasil (VIEIRA e DE SOUZA JUNIOR, 2006).

Com a criação da Lei n.․ 9.394/1996 (BRASIL, 1996), segunda LDB, foi removido o caráter assistencialista dado à educação profissional, tornando-a um mecanismo de inclusão social e certificação profissional (VIEIRA e DE SOUZA JUNIOR, 2006).

Após a segunda LDB e com o Decreto n.․ 2.208, de 17 de abril de 1997 (Brasil, 1997), o qual regulamentou a educação profissional e criou o Programa de Expansão da Educação Profissional (PROEP), (VIEIRA e DE SOUZA JUNIOR, 2006).

Com as sucessivas críticas ao decreto n.․ 2.208/97, foi criado o decreto n. 0 5.154/2004, e revogado o anterior, o qual criou a oportunidade de articulação entre a formação profissional e a humanística. Contudo, as alterações foram pontuais, assim 0 novo decreto não modificou significativamente o desenho operacional da educação profissional impresso pelo decreto anterior, mesmo agregando às modalidades de articulação 
anteriormente previstas (concomitante e sequencial), (VIEIRA e GANZERT, 2011).

\section{METODOLOGIA}

Conforme Marconi e Lakatos (2007), esta pesquisa se caracteriza como qualitativa e descritiva, sendo esta realizada através de pesquisa bibliográfica e documental em livros, periódicos, teses, dissertações, Leis, Decretos, entre outros. Foi identificado o panorama dos cursos profissionalizantes de nível médio presencial da rede estadual de ensino do Estado do Paraná, com base nos dados obtidos junto ao website da Secretária da Educação do Paraná (SEED).

\section{RESULTADOS E DISCUSSOES}

Os cursos técnicos de nível médio, conforme a Tabela 1, possuem diferentes modalidades sendo: integrado, que inclui formação profissional e ensino médio em um único curso (geralmente no mesmo período); concomitante, com cursos separados ao mesmo tempo (períodos diferentes); e subsequente, que corresponde à formação profissional após conclusão do ensino médio (VIEIRA e DE SOUZA JUNIOR, 2006). Além destas modalidades de cursos técnicos citadas, no Estado do Paraná existem mais duas modalidades disponíveis, sendo duas modalidades da Educação de Jovens e Adultos (EJA): Proeja-Integrado (para alunos que concluíram o ensino fundamental e possui 15 anos ou mais) e Proeja-Subsequente (para alunos que concluíram o ensino médio e possui 18 anos ou mais), (SEED, 2017).

No estado do Paraná os cursos técnicos de nível médio são ofertados gratuitamente a população, principalmente nas modalidades integrado e subsequente. Entretanto, também estão disponíveis em alguns municípios as modalidades: Proeja (Integrado e/ou subseqüente) e mediotec (comcomitante).

Conforme Seed (2018), no ano de 2018, no Estado do Paraná, estão matriculados 25.615 (36,41\%) estudantes nos cursos técnicos integrados, $28.459(40,45 \%)$ nos cursos técnicos subsequentes e 16.278 (23,13\%) no Curso de Formação de Docentes (antigo magistério integrado), totalizando 70.352 estudantes matriculados (FIGURA 1). 
Tabela 1: Modalidades de Cursos da Educação Profissional oferecidos na Rede Pública Estadual de ensino.

\begin{tabular}{cccc}
\hline $\begin{array}{c}\text { FORMA DE } \\
\text { OFERTA }\end{array}$ & PÚBLICO-ALVO & DISCIPLINAS & $\begin{array}{c}\text { DURAÇÃO } \\
\text { (anos) }\end{array}$ \\
\hline CONCOMITANTE & $\begin{array}{c}\text { Alunos matriculados a } \\
\text { partir do } 20 \text { ano do } \\
\text { Ensino Médio }\end{array}$ & Formação específica & 1 a 2 \\
INTEGRADA & $\begin{array}{c}\text { Concluintes do Ensino } \\
\text { Fundamental (9ํano) }\end{array}$ & $\begin{array}{c}\text { Educação Básica e } \\
\text { formação específica }\end{array}$ & 3 a 4 \\
PROEJA & $\begin{array}{c}\text { Concluintes do Ensino } \\
\text { Fundamental com idade } \\
\text { acima } 18 \text { anos (9o ano) }\end{array}$ & $\begin{array}{c}\text { Educação Básica e } \\
\text { formação específica }\end{array}$ & 3 \\
SUBSEQUENTE & $\begin{array}{c}\text { Concluintes do Ensino } \\
\text { Médio }\end{array}$ & Formação específica & 1 a 2 \\
\hline
\end{tabular}

Fonte: Adaptado de Seed (2019).

\section{Percentual de Alunos Matriculados}

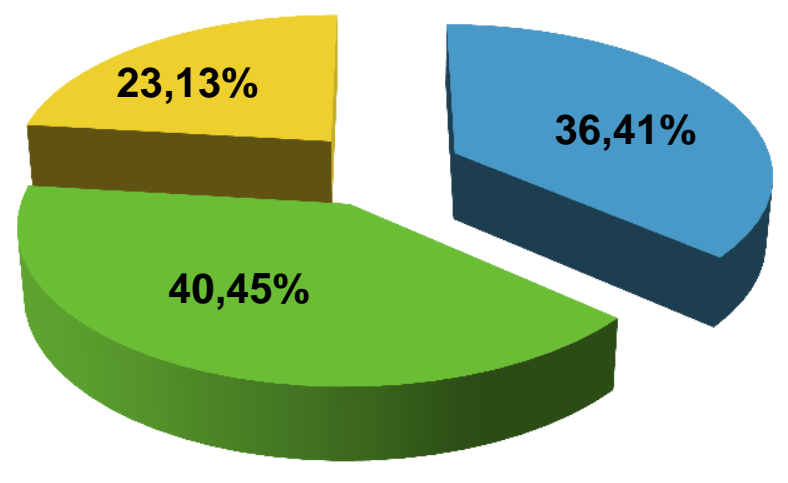

- Integrado

$\backsim$ Subsequente

- Formação doente

Figura 1: Percentual de Alunos Matriculados em Cursos da Educação Profissional oferecidos na Rede Pública Estadual de ensino do Estado do Paraná em 2018.

Fonte: Adaptado de Seed (2018).

Para o $1^{\circ}$ semestre de 2019 foram ofertadas 26.800 vagas em 54 cursos técnicos, além do curso de formação docente, em 183 municípios do 
Estado do Paraná, totalizando 351 estabelecimentos de ensino (SEED, 2018).

Atualmente, são ofertados cursos profissionalizantes divididos em 10 eixos tecnológicos: Ambiente e Saúde; Controle e Processos Industriais; Gestão e Negócios; Hospitalidade e Lazer; Informação e Comunicação; Infraestrutura; Produção Alimentícia; Produção Cultural e Design; Produção Industrial e Recursos Naturais (SEED, 2018).

Os seguintes cursos profissionalizantes foram ofertados na rede estadual de ensino no ano de 2019, nas modalidades, integrado e subsequente: Curso em Formação Docente, Curso Técnico em Administração, Agente Comunitário de Saúde, Agroecologia, Agroindústria, Agronegócio, Agropecuária, Alimentos, Análises Clínicas, Biotecnologia, Celulose e Papel, Comércio Exterior, Contabilidade, Cozinha, Cuidados de Idosos, Desenho de Construção Civil, Design de Interiores, Edificações, Eletroeletrônica, Eletromecânica, Eletrônica, Eletrotécnica, Enfermagem, Estética, Eventos, Farmácia, Florestas, Guia de Turismo, Hospedagem, Informática, Informática para Internet, Logística, Manutenção Automotiva, Manutenção e Suporte de Informática, Mecânica, Mecatrônica, Meio Ambiente, Nutrição e Dietética, Portos, Produção de Áudio e Vídeo, Prótese Dentária, Publicidade, Qualidade, Química, Recursos Humanos, Redes de Computadores, Saúde Bucal, Secretariado, Segurança do Trabalho, Serviços Jurídicos, Sistemas de Energia Renovável, Transações Imobiliárias, Turismo, Vendas e Vestuário (SEED, 2018).

Os cursos técnicos ofertados aos cidadões paranaenses, dependem da aptidão economica da região em questão, sendo os cursos do eixo tecnológico de Recursos Naturais os predominantes no interior do Estado, como, por exemplo, a região de Irati com predominância da atividade Florestal (IPARDES, 2017) possui o único curso Técnico em Florestas do Estado. Outro exemplo da influência do fator economico na oferta dos cursos técnicos, temos o curso Técnico em Guia de Turismo, ofertado na cidade de Foz do Iguaçu (também o único do Estado), conhecida região turistica. Já regiões industrializadas, como a região metropolitana de Curitiba, há a predominância de cursos dos eixos tecnológicos de Controle e Processos Industriais, e Produção Industrial (SEED, 2018).

\section{CONSIDERAÇÕES FINAIS}

A educação profissional teve um longo processo de consolidação no decorrer da historia do Brasil, sofrendo diversas modificações, que muitas vezes causaram algumas críticas por parte dos educadores, porém após o início da industrialização, estes cursos técnicos, foram essenciais para o desenvolvimento do parque industrial nacional. 
No Estado do Paraná temos 55 cursos técnicos de nível médio, espalhados por quase metade dos municípios paranaense, abrangendo a maioria dos setores da economia (cultura, turismo, indústria, comércio, saúde, agropecuário, entre outros), sendo de suma importância para o desenvolvimento econômico e social da população paranaense.

\section{REFERÊNCIAS}

BRASIL (1909). Decreto no. 7.566, de 23 de setembro de 1909. Crêa nas capitaes dos Estados da Republica Escolas de Aprendizes Artífices, para o ensino profissional primário e gratuito. Disponível em: http://www2.camara.leg.br/legin/fed/decret/1900-1909/decreto-7566-23setembro-1909-525411-publicacaooriginal-1-pe.html. Acesso em: 26 jan. 2019.

Brasil (1942). Decreto-lei no. 4.244, de 9 de abril de 1942. Lei orgânica do ensino secundário. Diário Oficial da União. Rio de Janeiro, 10 abr. 1942. Disponível em: http://www2.camara.leg.br/legin/fed/declei/1940-1949/ decreto-lei-4244-9-abril-1942-414155-publicacaooriginal-1-pe.html. Acesso em: 26 jan. 2019.

Brasil (1961). Lei no. 4.024, de 20 de dezembro de 1961. Fixa as Diretrizes e Bases da Educação Nacional. Diário Oficial da União. Brasília, 27 dez, 1961. Disponível em: http://www.planalto.gov.br/CCIVIL_03/LEIS/L4024.htm. Acesso em: 26 jan. 2019.

Brasil (1971). Lei no. 5.692, de 11 de agosto de 1971. Fixa diretrizes e bases para o ensino de $1 .^{\circ}$ e $2 .^{\circ}$ graus, e dá outras providências. Diário Oficial da União. Brasília, 12 ago.1971. Disponível em: http://www.planalto.gov.br/ ccivil_03/LEIS/L5692.htm. Acesso em: 26 jan. 2019.

Brasil (1996). Lei n.o 9.394, de 20 de dezembro de 1996. Estabelece as diretrizes e bases da educação nacional. Diário Oficial da União. Brasília, 23 dez. 1996. Disponível em: http://www.planalto.gov.br/ccivil 03/LEIS/L9394.ht m. Acesso em: 26 jan. 2019.

Brasil (1997). Decreto n.o 2.208, de 17 de abril de 1997. Regulamenta o § 2.. do art. 36 e os arts. 39 a 42 da Lei n.. 9.394, de 20 de dezembro de 1995, que estabelece as diretrizes e bases da educação nacional. Diário Oficial da União. Brasília, 18 abr. 1997. Disponível em: http://www.planalto.gov.br/ ccivil_03/decreto/D2208.htm. Acesso em: 26 jan. 2019. 
CANALI, H. H. B. A trajetória da educação profissional no Brasil e os desafios da construção de um ensino médio integrado à educação profissional. $V$ Simpósio Sobre Trabalho e Educação, 2009.

IPARDES (Instituto Paranaense de Desenvolvimento Econômico e Social). Mapas. 2017. Disponível em: http://www.ipardes.pr.gov.br/sites/ipardes/arqui vos_restritos/files/documento/201909/Valor\%20Bruto\%20da\%20Produ\%C3\% A7\%C3\%A30\%20-\%20Florestal\%20\%282017\%29.pdf. Acesso em: $17 \mathrm{dez}$. 2019.

MARCONI, M.; LAKATOS, E. M. Metodologia do trabalho científico: procedimentos básicos, pesquisa bibliográfica, projeto e relatório, publicações e trabalhos científicos. Atlas, 2007.

SEED (Secretaria de Estado da Educação). Cursos técnicos da rede estadual estão com inscrições abertas. 2017. Disponível em: http://www.educacao.pr.gov.br/modules/noticias/article.php?storyid=7243. Acesso em: 27 jan. 2019.

SEED (Secretaria de Estado da Educação). Cursos profissionalizantes recebem inscrições até segunda (19). 2018. Disponível em: http://www.educacao.pr.gov.br/modules/noticias/article.php?storyid=7753. Acesso em: 27 jan. 2019.

SEED (Secretaria de Estado da Educação). Cursos técnicos. 2019. Disponível em: http://www.comunidade.diaadia.pr.gov.br/modules/conteudo/ conteudo.php?conteudo=49. Acesso em: 20 jul. 2019.

VIEIRA, A. M. D. P.; DE SOUZA JUNIOR, A.. A educação profissional no Brasil. Interacções, v. 12, n. 40, 2017.

VIEIRA, Amanda Ribeiro; GANZERT, Christian Carvalho. Proeja como política pública de inclusão social: percepções dos alunos do curso técnico de administração do Campus Sertãozinho do instituto federal de São Paulo. Revista lluminart, v. 1, n. 6, 2011. Disponível em: http://revistailuminart.ti.srt.ifsp.edu.br/index.php/iluminart/article/view/106/110. Acesso em: 27 jan. 2019. 